\title{
Os direcionamentos teórico-metodológicos para formação inicial do professor de PLE na Universidade Federal da Bahia UFBA
}

\section{Theoretical-methodological guidelines for the initial training of the PFL teacher at the Federal University of Bahia UFBA}

\section{Aportes teóricos y metodológicos para la formación inicial del profesor de PLE en la Universidad Federal de Bahía UFBA}

\author{
Nathan Queiroz ${ }^{1}$ (i) https://orcid.org/0000-0002-3533-8832 \\ Iracema Luiza de Souza ${ }^{2}$ (D) https://orcid.org/0000-0002-7858-0135
}

\begin{abstract}
RESUMO: As Universidades públicas brasileiras ainda enfrentam uma escassa prática de formação docente quando se trata da área de Português Língua Estrangeira|Segunda Língua (PLE\PL2), desta forma, este trabalho objetiva apresentar os direcionamentos teóricometodológicos utilizados na formação do professor de PLE na Universidade Federal da Bahia (UFBA). Em um primeiro momento, o professor em formação é convidado a utilizar os preceitos estabelecidos por Schön (2000) para estar constantemente (re)pensando sua prática docente. Em seguida, relacionando-o com as ideias propostas por Clark (2000), Antunes (2009) e Mendes (2012), o professor é capaz de elaborar atividades que cumpram os propósitos linguísticos do curso de PLE, esse movimento de elaboração é embasado por Silva e Leurquin (2014). Tendo esse cenário como pano de fundo, relatamos aqui algumas das atividades que foram desenvolvidas e aplicadas pelo professor em formação durante sua atuação no NUPEL, UFBA. Por fim, refletimos sobre suas consequências tanto para o ensino em PLE quanto para a formação dos professores na área.
\end{abstract}

PALAVRAS-CHAVE: Direcionamentos teórico-metodológicos. Formação em PLE. UFBA.

ABSTRACT: Brazilian public universities still face a scarce practice of teacher training when it comes to the area of Portuguese as a Foreign LanguagelSecond Language (PFL\PSL). Thus, this study aims at presenting the theoretical-methodological guidelines used in the training of the PFL

\footnotetext{
1 Mestrando em Estudos da Linguagem, Universidade Federal do Rio Grande do Sul (UFRGS). Licenciado em Letras Português Língua Estrangeira, Universidade Federal da Bahia (UFBA). E-mail: Nq.queiroz@gmail.com.

2 Professora titular da Universidade Federal da Bahia (UFBA). E-mail: Iracema souza@uol.com.br .
} 
teacher at the Federal University of Bahia (UFBA). At first, the teacher in training is invited to use the precepts, established by Schön (2000), to be constantly (re)thinking his teaching practice. Then, in relation to the ideas proposed by Clark (2000), Antunes (2009) and Mendes (2012), the educator is able to create activities that fulfill the linguistic purposes of the PFL course, the creation process is supported by Silva and Leurquin's (2014) theory. Using this scenario as a background, we report some activities that were developed and applied by the teacher-in-training during his performance at NUPEL, UFBA. Finally, we reflect on the consequences of these activities for the teaching practice in PFL and for the training of teachers in the area.

KEYWORDS: Theoretical-methodological guidelines. Teacher-in-training. UFBA.

RESUMEN: Las universidades públicas brasileñas aún enfrentan una escasa práctica de formación docente en el área de portugués como lengua extranjera \segunda lengua (PLE \PL2), por lo que este trabajo tiene como objetivo presentar los aportes teóricos y metodológicos utilizados en la formación del docente de PLE de la Universidad Federal de Bahía (UFBA). En un primer momento, se invita al docente en formación a utilizar los preceptos establecidos por Schön (2000) para estar constantemente (re)pensando su práctica docente. Luego, relacionándolo con las ideas propuestas por Clark (2000), Antunes (2009) y Mendes (2012), el docente es capaz de elaborar actividades que cumplan con los propósitos lingüísticos del curso PLE, este movimiento de elaboración es apoyado por Silva y Leurquin. (2014). Con este escenario como trasfondo, narramos aquí algunas de las actividades que fueron desarrolladas y aplicadas por el docente en formación durante su actuación en NUPEL, UFBA. Finalmente, reflexionamos sobre sus consecuencias tanto para la docencia en PLE como para la formación del profesorado del área.

PALABRAS CLAVE: Aportes teóricos y metodológicos. Profesor en formación. UFBA.

\section{Introdução}

A internacionalização da Língua Portuguesa vem tomando forma no Brasil, principalmente dentro do espaço acadêmico universitário, onde se discutem parâmetros para o ensino e formação em Português Língua Estrangeira\Segunda Língua (PLE\PL2) bem como a criação de instrumentos linguísticos que atendam a esse mercado de línguas (DINIZ, 2008). Entretanto, as Universidades públicas brasileiras ainda enfrentam uma escassa prática de formação docente quando se trata da área de PLE\PL2 ${ }^{3}$. Isso se deve, entre outros fatores, à falta de políticas linguísticas que regulamentem a formação desse profissional, deixando essa atividade a cargo das Instituições de Ensino Superior. Dessa forma, as Instituições que possuem essa prática realizam-na de maneira distinta trabalhando de acordo com o cenário em que se inserem e com as ferramentas que possuem. Ainda que a política linguística não se trate exclusivamente de uma obrigação governamental ou um ato solene, é importante se ater aos espaços deixados pela

\footnotetext{
3 Além do uso de PLE\PL2 há também outras formas de se referir ao ensino da Língua Portuguesa para falantes de outras línguas. Para uma maior discussão sobre as terminologias empregadas na área, consultar Bulla e Kuhn (2020).
} 
ausência dela enquanto processo político. Atualmente, o Brasil conta com apenas quatro cursos de Licenciatura em PLE\PL2 institucionalizados, esses cursos se desenvolvem a partir de abordagens e cenários distintos, mas com o mesmo objetivo, formar professores de línguas profissionais capacitados e humanamente sensíveis ao processo intercultural no ensino do português LE L2.

Desde 19564 que o ensino e formação em Português como Língua Estrangeira vem se desenvolvendo através da prática docente e também de pesquisas e produções que buscam sempre refletir o cenário corrente do período em que se desenvolve. Entretanto, foi somente a partir de 1998 que a licenciatura em PLE se tornou uma realidade. Esse passo inicial foi dado pela Universidade de Brasília (UNB), que instituiu a primeira licenciatura para formar professores de Português como Segunda Língua em uma Universidade pública brasileira (NIEDERAUER et al., 2020, p. 20).

Sete anos depois, em 2005, era a vez da Universidade Federal da Bahia (UFBA) dar início ao curso de licenciatura em Português Língua Estrangeira/Segunda Língua. Torna-se necessário ressaltar que tal institucionalização resulta de uma tradição de ensino de Português a falantes de outras línguas, iniciada nos anos sessenta, para atender à demanda de estudantes que chegavam de diversos países da África, América do Sul e Caribe para cursarem a graduação no Brasil através do Programa de Estudantes Convênio - PEC-G. Os cursos de Português LE/L2, destinados ao atendimento dessa demanda sofreram interrupções provocadas por questões de infraestrutura, embora a UFBA continuasse a oferecer aulas de Português a estudantes de diferentes nacionalidades que vinham ao Brasil por iniciativa própria, bem como sob o patrocínio de universidades estrangeiras localizadas no Canadá, no México, na Alemanha, França e Itália.

Em 1986, a Profa. Iracema Luiza de Souza foi convidada a criar e coordenar uma comissão que teve por meta elaborar um projeto que institucionalizasse, na UFBA, o ensino de Português para Estrangeiros. Assim, foi elaborado o Projeto do Centro de Ensino de Português para Estrangeiro (CEPE), que foi criado em abril de 1991. Em 1999, a Profa. Iracema Luiza de Souza credencia o Posto Aplicador da UFBA em e exerce sua coordenação a partir de então. No ano 2000, foi aprovada a implantação do Programa

\footnotetext{
4 "No Brasil, a história moderna do ensino de português língua estrangeira (EPLE) tem um marco simbólico iniciado na publicação, em Porto Alegre, do livro didático O Ensino de Português para Estrangeiros, de autoria de Mercedes Marchandt em 1956" (ALMEIDA FILHO, 2018. p. 16).
} 
de Pesquisa, Ensino e Extensão de Português - ProPEEP, que ampliou as ações de ensino em PLE $\mid P L 2$, incentivou as pesquisas na área e ainda serviu de base para a criação da licenciatura em português para falantes de outras línguas.

Após a UFBA, foi a vez da Universidade Federal da Integração Latino-Anericana (UNILA), em 2015, apresentar o curso de licenciatura em Letras Espanhol e Português como Língua Estrangeira, contribuindo para um cenário intercultural de formação que busca o intercâmbio acadêmico e a cooperação solidária entre os países da américa latina, sobretudo do MERCOSUL (CARVALHAL, 2020, p. 64). Por fim, somando ao quadro das quatro universidades públicas brasileiras que oferecem essa licenciatura, a Universidade Estadual de Campinas (UNICAMP) implementou, em 2015, no catálogo de cursos da instituição, o curso de PLE\PL2, passando a ofertar as disciplinas a partir do primeiro semestre de 2017 (SCARAMUCCI; BIZON, 2020, p. 100). O processo de implementação dessas licenciaturas teve por bases os processos políticos e econômicos, de seus respectivos períodos, que afetavam o status da língua portuguesa brasileira no mundo. Foram necessárias atmosferas distintas para que cada Universidade pudesse institucionalizar a formação de professores de PLE\PL2. Sobre esse processo, Scaramucci e Bizon (2020, p. 100) afirmam que houve uma influência direta do:

Papel emergente do Brasil como protagonista em políticas de expansão econômica, de transnacionalização da língua portuguesa e de internacionalização de suas universidades [...] ampliando as demandas para o ensino da língua portuguesa. Envolveu também processos de globalização mais recentes, assim como as condições geopolíticas complexas que produziam e continuam produzindo deslocamentos populacionais de diferentes ordens, com constantes redefinições dos espaços transnacionais.

Esse cenário não é estanque e continua produzindo demandas para o ensino e aprendizagem da Língua Portuguesa. Outras Universidades seguem trabalhando para a promoção da LP e, consequentemente, para a institucionalização de cursos que formem professores para essa área. "As licenciaturas existentes, em linhas gerais, apresentam objetivos similares, mas ainda assim trazem muitas especificidades, que são justamente o reflexo da diversidade dos contextos políticos, culturais e educacionais em que os cursos se desenvolvem" (MENDES, 2020, p. 44).

Posto o cenário atual da formação inicial dos professores de PLE\PL2 no Brasil, este trabalho tem o objetivo de apresentar os direcionamentos teórico-metodológicos 
utilizados na formação do professor de PLE na UFBA, com base nos relatos de experiência do professor em formação durante o período de atuação no Núcleo Permanente de Extensão em Letras (NUPEL) 5 . Para isso, fizemos primeiramente uma apresentação sobre as ferramentas de formação oferecidas pela UFBA, em especial o NUPEL. Em seguida, apresentamos as práxis realizadas pelo professor em formação durante o referido período, trazendo exemplos de atividades desenvolvidas em sala de aula. Por fim, ressaltamos a importância de se construir direcionamentos que dialoguem com os propósitos do ensinolaprendizagem de PLE.

\section{A formação inicial dos professores de PLE na UFBA}

A formação inicial do professor de PLE\PL2 na UFBA se baseia no princípio da interculturalidade, buscando preparar o professor para:

Agir na diversidade, sendo capaz de compreender os fenômenos mais amplos da globalização como inevitáveis e profundamente determinantes dos comportamentos sociais e consequentemente, interacionais, que vão afetar o seu ambiente educacional em maior e menor escala. Uma formação adequada deve dar ao professor ferramentas para lidar com a adversidade, a descriminação, a exclusão social, que afetam seriamente muitas salas de aula de língua, realidade cada vez mais frequente com relação ao português, nos diferentes cantos do mundo (RODRIGUES; OLIVEIRA; MENDES, 2020, p. 667).

Dessa forma, os estudantes da licenciatura em PLE na UFBA estão sempre refletindo sobre sua prática de formação docente em diálogo com a realidade em que vivem, buscando interpretá-la através da língua. Pensando nessa proposta, a Universidade oferece dois projetos institucionais de formação: o Programa Especial de Monitoria de Português como Língua Estrangeira (PROEMPLE) ${ }^{6}$ e o Núcleo Permanente de Extensão em Letras (NUPEL) ${ }^{7}$, que será abordado e discutido aqui de maneira mais profunda.

O NUPEL, criado em 2012, visa promover a articulação da extensão com o ensino

\footnotetext{
${ }^{5}$ Este artigo parte do relato de experiência do professor em formação, Nathan Queiroz, durante sua atuação no NUPEL, de 2018 a 2019, sob orientação da Profa. Dra. Iracema Luiza de Souza.

${ }^{6}$ Rodrigues (2019) se debruça sobre as percepções de aprendizagem dos alunos estrangeiros que fazem parte do PROEMPLE, buscando refletir de que forma se dá esse processo de aprendizagem e quais os aspectos positivos e negativos dessas abordagens. Para mais informações sobre o PROEMPLE, consultar Rodrigues (2019).

${ }^{7}$ Ver http://www.nupel.ufba.br/
} 
e a pesquisa e tem se consolidado como espaço de formação docente no qual os estudantes podem, entre uma das práticas ofertadas, experimentar a práxis em sala de aula. O Núcleo conta com a oferta de doze cursos de línguas, entre eles, Grego, Yorubá, Kimbundo e PLE, todos ofertados à comunidade externa e interna da UFBA, ampliando a relação entre a Universidade e a sociedade. Todos os professores que atuam no NUPEL são alunos da graduação ou pós-graduação em Letras. O estudante ingressa mediante edital e, atendendo a todos os requisitos necessários para atuar como Professor em Formação (PF) daquela língua, poderá ficar por um período de até quatro semestres. Durante sua formação dentro do Núcleo, o PF dispõe de uma equipe de coordenação que oferece todo suporte necessário para sua atuação, bem como a orientação por um professor da área. Essa orientação é a peça-chave para poder se construir uma base teórico-metodológica que auxiliará no seu processo de formação e atuação em sala de aula. Além disso, o PF deve participar de encontros trimestrais sobre formação docente, os quais buscam complementar e discutir a prática em sala de aula com o objetivo de proporcionar um momento de aprendizagem, interação e troca entre os PFs. Dessa forma, o professor em formação poderá perceber seu amadurecimento profissional ao longo desse período.

Convém aqui esclarecer que a capacitação dos estudantes para o exercício docente compõe-se de duas vertentes: uma, que se sustenta numa grade curricular inovadora, que se propõe a envolver os aprendizes na discussão das abordagens mais atualizadas oferecidas pela Linguística Aplicada. Nela, são produzidas discussões críticas sobre ensino e aprendizagem de língua não-materna, com foco na perspectiva da interação verbal, sobre as habilidades de fala, leitura e escrita, do ponto de vista do discurso. A licenciatura possibilita também discussões frutíferas sobre avaliação de proficiência e de desempenho. Essas considerações aqui formuladas dizem respeito à formação de todos os estudantes que optaram pela licenciatura objeto do presente trabalho. A outra vertente da capacitação dos docentes que optaram por PLE diz respeito às oportunidades que lhes são disponibilizadas através do NUPEL e do PROEMPLE.

No período que aqui será relatado, 2018 e 2019, a área de Português para Estrangeiros do NUPEL contava com dois estudantes bolsistas e um professor orientador. À época, eram ofertadas quatro turmas de PLE, Básico I, Básico II, Intermediário e Avançado. $O$ público estudantil que buscava aprender português não se caracterizava por 
um público específico, mas sim por uma pluralidade cultural constante ${ }^{8}$. Todas as turmas eram diversas e contavam com, no mínimo, cinco nacionalidades. Essa configuração intercultural foi importante para se pensar de que forma a área de PLE se apresenta e como isso influencia no processo intercultural de ensino-aprendizagem, pois o curso de PLE ofertado pelo NUPEL "destina-se tanto a estrangeiros recém-chegados ao Brasil, sem qualquer conhecimento da língua portuguesa, quanto àqueles que já são capazes de se comunicar em português e queiram aperfeiçoar a sua proficiência oral e escrita" (CRUZ, 2019 , p. 51) $)^{9}$.

O primeiro passo dentro do Núcleo foi entender o que é ser um professor em formação. Para isso, fomos direcionados a pensar no papel do professor reflexivo, partindo dos preceitos estabelecidos por Donald Schön (2000). Schön defende que a reflexão é baseada nas experiências vividas pelo indivíduo. Precisamos refletir sobre aquilo que vivemos ou experimentamos para, a partir daí, entender o que foi aprendido. O autor defende a importância de uma prática reflexiva baseada no conhecimento da ação e em três tipos de reflexão, a saber: a reflexão sobre a ação, a reflexão na ação e a reflexão sofre a reflexão na ação.

A reflexão sobre a ação consiste em pensar a prática docente, sobre o que deve ser ensinado, para quem e na forma como isso se dará. Schön (2000) nos leva a pensar de que maneira projetamos nossas ações sobre os outros e quais resultados esperamos delas. Em seguida, partimos para a reflexão na ação, que consiste em refletir durante a prática. Sempre que estamos apresentando um conteúdo para os alunos, nos perguntamos se eles estão entendendo a mensagem passada e caso percebamos que esse troca de informações não está ocorrendo, reinventamos todo nosso repertório e conduzimos nossa prática por um caminho completamente diferente a fim de atender o mesmo objetivo. Esse momento de reflexão é enfatizado por Schön e se configura como a valorização da prática profissional em um momento de construção do conhecimento tácito.

No momento seguinte, o autor defende a reflexão sofre a reflexão na ação, ou

\footnotetext{
${ }^{8}$ As turmas de estudantes do PROEMPLE, por serem direcionadas ao programa PEC-G, apresentam características mais rígidas. Em sua maioria, alunos de países africanos.

${ }^{9}$ Cruz (2019) desenvolveu sua pesquisa com o objetivo de propor o blog como um ambiente favorável ao ensino de português LE/L2 em uma perspectiva intercultural e crítica, para tanto, utilizou as aulas do NUPEL como laboratório de pesquisa.
} 
seja, "quando pensamos retrospectivamente sobre o que fizemos, de modo a descobrir como nosso ato de conhecer-na-ação pode ter contribuído para um resultado inesperado" (SCHÖN, 2000, p. 32). Essa etapa se configura em refletir não só sobre a prática em sala de aula, mas também sobre o pensamento-ação durante a prática. Em resumo, o que se defende com a prática reflexiva é uma formação mais assertiva do professor, para que ele aprenda a estar apto a lidar com futuros desafios em sala de aula, refletindo sobre esses desafios e apresentando diferentes soluções. O professor se forma a partir da reflexão sobre a ação. É partindo de um constante pensar sobre sua performance que esse profissional irá se entender enquanto docente e enquanto formador. Claramente, 0 processo de refletir com e para a ação não foi realizado somente durante o período no NUPEL. Essa é uma prática que acompanha os professores e vem servindo de mola propulsora para (re)pensar suas performances enquanto docentes, entendendo sempre que estão em constante formação.

\section{Especificações para formação em PLE}

No que se refere aos direcionamentos teórico-metodológicos do professor de PLE em específico, é necessário pensar em referências que busquem embasar uma prática intercultural e humanamente sensível, como foi abordado anteriormente. Dessa forma, é trabalho do professor orientador estabelecer quais serão os aportes teóricos discutidos durante a formação do PF no NUPEL. Esses referenciais são selecionados com base nos objetivos que se pretendem atingir em sala de aula e em quais habilidades deverão ser desenvolvidas pelo professor nesse processo de formação.

No entanto, é importante ressaltar a inexistência de um documento que regulamente a formação do professor de PLE no Brasil. À época deste relato ocorrido no NUPEL (2018-2019), não havia qualquer documento oficial ou institucional que tratasse especificamente da formação desse profissional. Schoffen e Martins (2016) apresentam as perspectivas portuguesa e brasileira para o ensino de português como língua estrangeira, com objetivo de apontar os contrastes existentes entre essas duas orientações teóricas. Em seu estudo, os autores apresentam os documentos elaborados por Portuga ${ }^{10}$ para o ensino de PLE em contraste com a não existência de documentos

\footnotetext{
10 Os documentos são: "Português Língua Não Materna no Currículo Nacional: Documento Orientador"; "Orientações Programáticas de Português Língua Não Materna (PLNM): Ensino Secundário" e o "Quadro de Referência para o Ensino
} 
Os direcionamentos teórico-metodológicos para formação inicial do professor de PLE na Universidade Federal da Bahia UFBA

elaborados pelo Brasil para essa finalidade, para tanto, utilizam os documentos oficiais do exame Celpe-Bras e mostram que embora Portugal possua tais documentos, esses não têm utilidades quando aplicados ao ensino da língua portuguesa no Brasil, dessa forma, os autores enfatizam a importância da redação de parâmetros curriculares brasileiros para o ensino de PLE, "a fim de consolidar a perspectiva brasileira e servir de base para a definição de currículos, a elaboração de materiais didáticos e a formação de professores" (SCHOFFEN; MARTINS, 2016, p. 271).

Esse cenário foi levemente modificado em abril de 2020 quando o Ministério das Relações Exteriores (MRE) divulgou a coleção Propostas Curriculares para Ensino de Português no Exterior, que objetiva preencher a lacuna metodológica em suas unidades de ensino de português no exterior ${ }^{11}$. Apesar das ressalvas ao material, acreditamos que esse documento pode ser considerado como o início de um referencial curricular orientador para o ensino de PLE. Além disso, também em 2020, o Instituto Nacional de Estudos e Pesquisas Educacionais Anísio Teixeira (INEP) publicou o Documento-Base do Exame CELPE-Bras ${ }^{12}$, que apresenta o construto do exame e sua operacionalização nas partes escrita e oral (BRASIL, 2020, p. 27). Os documentos relacionados ao CELPE-Bras já vinham servindo como referencial tanto para a pesquisa na área quanto para as aulas de PLE, e as tarefas propostas pelo exame servem de orientação aos professores a respeito de como direcionar algumas de suas práticas pedagógicas. Tanto as Propostas Curriculares quanto o Documento-Base representam um marco na área de PLE. Ainda que não tratem da formação do professor em especial, são, até o momento, os únicos documentos oficiais voltados ao ensinolaprendizagem de PLE. Dito isso, voltando ao cenário em que nenhum desses documentos existia, ficava a cargo da Universidade decidir como seria feita essa formação ${ }^{13}$. Para tanto, o professor orientador iria se basear nas pesquisas realizadas até aquele período, a fim de fornecer um direcionamento teórico

\footnotetext{
Português no Estrangeiro" (SCHOFFEN; MARTINS, 2016, p. 272).

${ }^{11}$ Os guias curriculares permitem harmonizar o conteúdo dos cursos de português oferecidos pelos centros culturais e núcleos de estudos do Itamaraty no exterior [...]. Embora pensadas a partir das necessidades de sua rede de postos, as propostas não se destinam exclusivamente ao ensino de português pelos centros culturais e núcleos. Professores, pesquisadores e estudantes de quaisquer instituições poderão beneficiar-se desse pioneiro esforço de reflexão como referência para o desenvolvimento de suas práticas docentes e de pesquisa. (EXTERIORES, Ministério das R., 2020) ver: Brasil, [2021].

12 "Espera-se que o Documento seja uma fonte de inspiração e referência em direção ao aprofundamento da reflexão, ao avanço teórico e à ação na educação linguística, contribuindo para a disseminação e valorização do Exame e para a promoção do ensino de português para estrangeiros no Brasil e no exterior" (BRASIL, 2020, p. 14).

${ }^{13}$ Importante lembrar que ainda é responsabilidade das universidades formar os profissionais de acordo com suas propostas de atuação pedagógica.
} 
sólido que culminasse numa práxis eficaz. O primeiro passo para essa prática era entender a noção de língua. Em seu estudo, Mendes (2012) apresenta a pesquisa desenvolvida com os alunos da licenciatura em Letras da UFBA. Nele a autora buscava compreender o que pensavam esses alunos em relação à ideia de língua que estavam construindo. Através da sua análise, Mendes verificou que $71 \%$ dos estudantes entendiam a língua como instrumento de comunicação ou conjunto de signos que tem como objetivo a comunicação, ao passo que $6 \%$ entendiam a língua como lugar de interação e como atividade situada socioculturalmente. A partir desses dados, é possível verificar de que forma os estudantes entendem a língua que estudam e a língua que ensinarão.

O objetivo de Mendes (2012) não era estabelecer se existia ou não uma visão correta de língua, mas traçar um panorama em que fosse possível verificar as diferentes perspectivas que se tem sobre um mesmo objeto e de que forma isso influencia em nossa formação. Diante disso, a autora defende que "não há concepções melhores ou piores, corretas ou incorretas, mas sim adequadas aos objetivos de pesquisa e/ou de ensino tomados como referência, bem como aos contextos em que se desenvolvem essas ações" (MENDES, 2012, p. 667). Assim, pensando no ensino do português enquanto língua estrangeira inserido em um contexto intercultural, os direcionamentos teóricos adotados consistiam em pensar a língua como conjunto de procedimentos que envolvem seu uso social, tomando por base principalmente os preceitos de Clark (2000) e Antunes (2009).

\section{Abordagens iniciais e mapeamento}

Como mencionado anteriormente, as turmas do NUPEL eram compostas por alunos de diversas nacionalidades, mas alocados em níveis correspondentes. O curso começava no primeiro momento em que o professor em formação se reunia com o orientador para traçar as ferramentas e objetivos daquele período de aula. Juntos, tendo em mãos o perfil da turma, professor e orientador planejavam estratégias de ensino. 0 planejamento não era algo rígido, muito pelo contrário, servia como bússola para guiar o $\mathrm{PF}$ à medida que as aulas iam acontecendo.

Uma prática recorrente entre os professores de PLE do Núcleo era construir, no primeiro dia de aula, um mapa da turma. Era uma atividade dinâmica que trazia informações extremamente importantes a respeito da trajetória de aprendizagem deles. Em uma folha de papel, os PFs dividiam em seções alguns pontos importantes que 
gostariam de saber sobre os alunos, por exemplo: 1) Quais suas dificuldades e seu pontos fortes na Língua Portuguesa?; 2) Qual a melhor forma para você aprender um outro idioma?; 3) O que mais te encanta na Língua Portuguesa?; 4) O que mais te encanta na cultura brasileira?; 5) O que você gostaria de aprender aqui no curso?; 6) Como você se imagina ao final do curso? Essas perguntas eram estrategicamente colocadas nessa ordem para que os alunos pudessem pensar os pontos fortes e fracos na hora de se aprender uma língua, o que eles já sabiam e o que eles gostariam de aprender. Em seguida, os PFs distribuíam post it para que os alunos colocassem suas respostas nos blocos de nota e adesivassem no mural ${ }^{14}$.

Não se pode esperar que seus alunos saibam todas as respostas, muitas vezes é a primeira vez que eles estão aprendendo uma segunda língua e tudo aquilo é completamente novo. Porém, é de extrema importância instigar o aluno a pensar sobre seu percurso de aprendizagem, tornando-o cada vez mais autônomo. Ao final da atividade, pendurávamos o mapa na lousa para que pudéssemos ler algumas das respostas dadas e assim conversar com eles a respeito das expectativas durante o curso. Essa etapa era feita juntamente com os objetivos propostos pelo NUPEL, disponíveis na página do Núcleo15, onde há, para cada nível, a progressão esperada durante aquela etapa do processo.

Os dados gerados por essa simples atividade traziam inúmeras ideias ao professor durante o semestre. Primeiro, pensar quais os pontos fortes e fracos de cada aluno, para poder entender o que deveria ou não trabalhar. Segundo, entender como os alunos geralmente aprendiam. Essa questão gerava respostas interessantes, porque grande parte dos alunos escrevia "com a gramática". É importante, durante as aulas de PLE, que o aluno tenha consciência de que a gramática é um recurso, assim como tantos outros, que faz parte do processo de aprendizagem, mas não guia o processo em si. Por diversas vezes, o PF se deparava com situações em que os alunos perguntavam: mas qual o certo? o certo é falar tu ou você? entre outras questões que eventualmente surgiam na aula de PLE. Terceiro, estabelecer metas alcançáveis. Nenhum aluno escolhe aprender uma outra língua sem uma razão específica, existe um motivo por trás dessa escolha, e é esse

\footnotetext{
14 É interessante pensar que esse mapeamento também pode ser implementado em aulas virtuais, utilizando ferramentas como o Padlet ou o Jamboard.

15 Ver: http://www.nupel.ufba.br/portugues
} 
motivo que precisamos, enquanto professores, tornar palpável.

É necessário que a partir desse mapa, o professor comece a pensar em estratégias, ferramentas e atividades para utilizar com aquele grupo específico de alunos. 0 professor não pode ser uma entidade rígida que aplica as mesmas atividades e os mesmo métodos para todas as turmas que por ventura passem por ele. É preciso se reinventar, se atualizar e estar em constante processo de reflexão, como afirma Schön (2000).

\section{Pós-mapeamento e elaboração de material}

O acervo de materiais didáticos para PLE que existe hoje no mercado é enorme. Mas ainda assim os professores seguem produzindo seus próprios materiais, essa é uma escolha lógica que se apoia no fato de que nenhum material consegue contemplar a variação linguístico-cultural presente no Brasil e, por muitas vezes, não se adequam à realidade local de onde se está aprendendo a língua. Dessa forma, em Silva e Leurquin (2014), é apresentada uma dinâmica que propicia ao professor refletir sobre a criação do material didático, "não mais como um reprodutor de conteúdos e de atividades distante da realidade, mas como autor e, sobretudo como pesquisador dos fatos da linguagem" (SILVA; LEURQUIN, 2014, p. 6). A dinâmica, como apresentada abaixo, guiou os professores de PLE do NUPEL no momento em refletir sobre a criação desses materiais, tendo em vista os direcionamentos teóricos que dispunham, bem como o mapa da turma realizado no primeiro dia de aula.

Figura 1 - Processo de elaboração do material didático

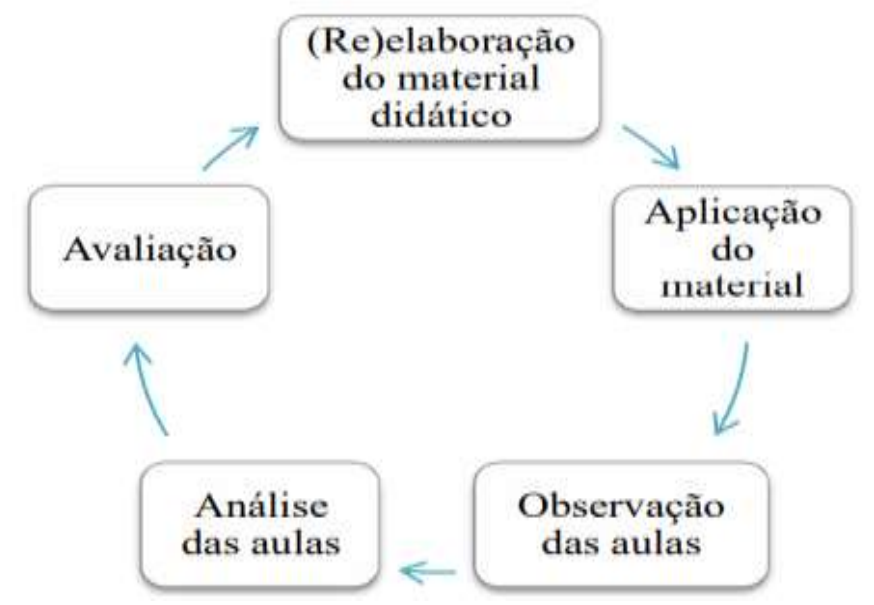

Fonte: Silva e Leurquin (2014, p. 6)

Partindo dessa dinâmica de refletir sobre a criação do material didático juntamente com a prática de ensino, o processo de formação do professor se torna cada vez mais engrandecedor. Foi a partir desses direcionamentos, em diálogo com as teorias 
estudadas, que foram elaboradas as atividades apresentadas a seguir, ambas desenvolvidas com as turmas de nível avançado e que apresentaram desdobramentos importantes para os alunos e para pesquisa em sala de aula.

\section{Língua na cultura}

Durante o mapeamento da turma, no primeiro semestre de 2019, foi possível perceber que um número significativo de alunos havia colocado "filmes" como uma das ferramentas de aprendizagem. A partir disso, buscamos literaturas que tratassem da relação entre cinema e aula de línguas, mais especificamente as aulas de PLE. Após algumas leituras (BULEGON, 2017; BULEGON; BULLA, 2018), elaboramos uma atividade que tentasse integrar as três habilidades de fala, escrita e escuta. Em uma aula anterior, o PF conversou com os alunos sobre o cinema nacional a fim de sondar o que havia de conhecimento ali. Consequentemente, os alunos da América Latina conheciam mais filmes nacionais que os alunos de outros continentes. Eles relataram o que sentiram ao assistir determinados filmes, como aqueles filmes influenciaram na vida deles etc., conversamos um pouco sobre como funciona o cinema no Brasil, questões de preços, localização, entre outros fatores. Naquele mesmo semestre, alguns alunos haviam feito a carteirinha de estudante na Universidade, o que permitia a eles um desconto nos ingressos de cinema.

$\mathrm{Na}$ aula seguinte foi apresentada a atividade que havia sido planejada. Em uma mesa grande, foi colocada uma série de cartazes de filmes, todos coloridos, impressos em folha de papel A4. Selecionados previamente, os cartazes continham temas variados, alguns famosos, outros nem tanto. É importante nesse momento da atividade que o professor conheça os filmes e selecione aqueles que tragam discussões interessantes para a turma, isso só será possível conhecendo o perfil dos alunos. Ao dispor os cartazes na mesa, foi solicitado que eles olhassem com calma, analisassem os títulos, as cores, as imagens etc., ao fim poderiam escolher o cartaz que mais lhe chamasse a atenção. Em seguida, cada aluno mostrava para a turma o cartaz que escolhera e dizia os motivos de ter escolhido aquele cartaz. 


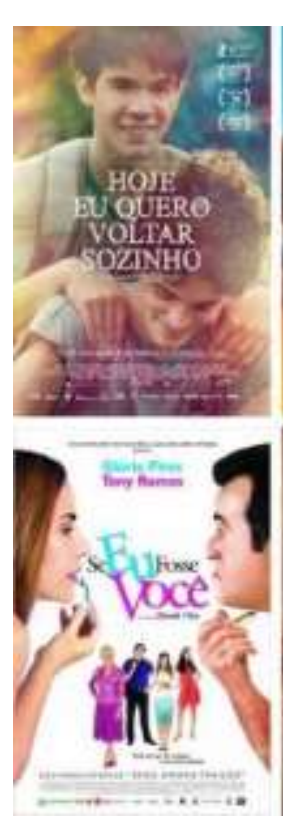

Figura 2 - Exemplo dos cartazes utilizados na atividade
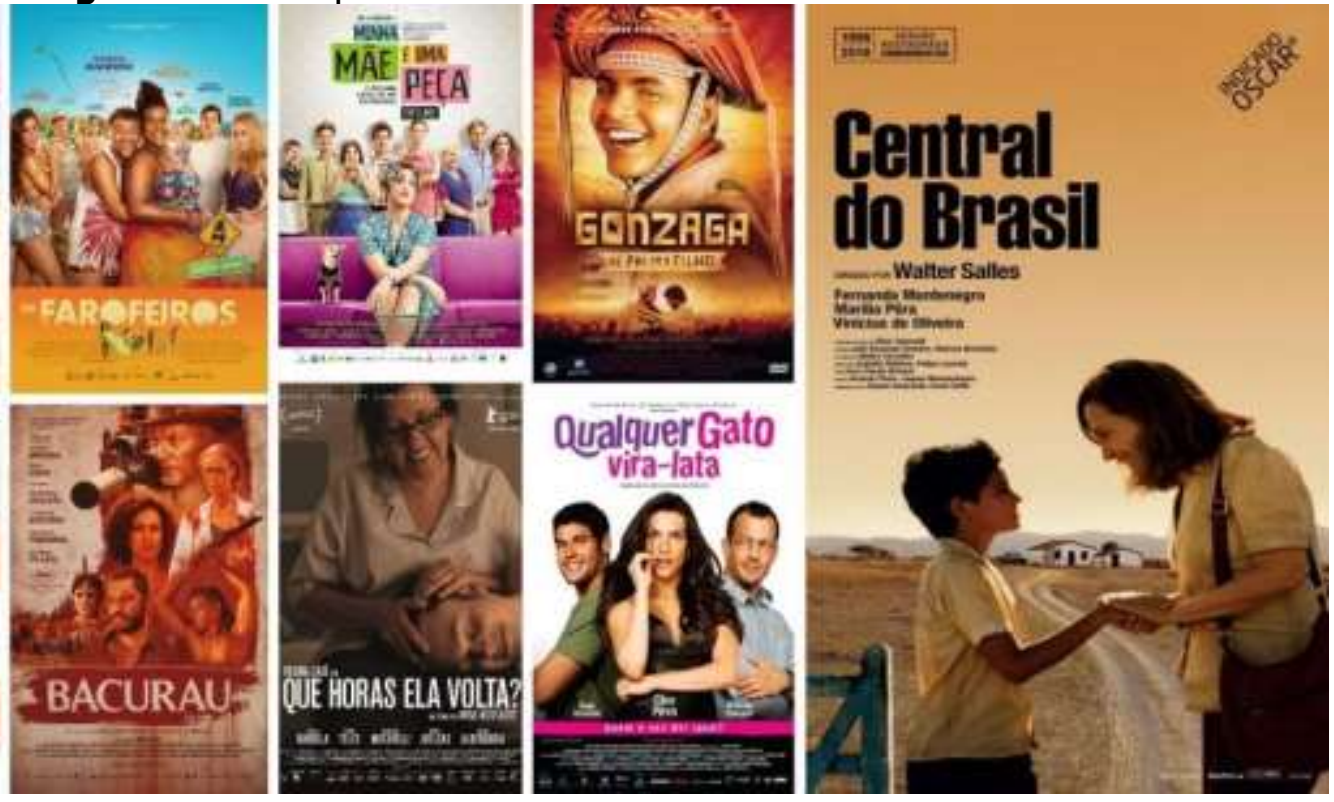

Fonte: Elaborado pelos autores.

Solicitou-se, então, que eles imaginassem como seria aquele filme que eles tinham em mãos. Como seria o roteiro ${ }^{16}$, como seriam os personagens, onde ele acontecia etc., a partir disso os alunos deveriam escrever um resumo do filme. Nesse momento da atividade, os comandos das tarefas do exame CELPE-Bras foram utilizados como base: "imagine que você assistiu ao filme e deseja escrever a um amigo contando a história...", por entender que tais comandos conseguem contemplar as ferramentas importantes para a construção da atividade, como gênero, interlocutor, suporte, propósito etc.

Após a finalização da atividade, os alunos, um de cada vez, apresentaram seus textos para a turma. Foi um momento divertido porque eles abusaram da criatividade e criaram várias histórias, alguns foram para a comédia, outros para a ação e cada um escreveu dentro de um gênero no qual se sentia mais confortável. Ao final de cada leitura, era exibido o trailer do filme que o aluno havia escolhido e, juntos, a turma conversava se a história criada pelo aluno era parecida ou não com o roteiro original do filme. Ousamos dizer que, em alguns casos, as histórias criadas pelos alunos eram infinitamente mais interessantes que a história original. Posteriormente, todos os textos foram corrigidos e eles receberam feedbacks individuais sobre a escrita. Essa atividade instigou neles o desejo de conhecer mais sobre o cinema nacional e ainda trabalhou as três habilidades que mencionamos, fala - no momento em que justificavam o cartaz escolhido

${ }^{16}$ É necessário que o professor tenha trabalhado anteriormente os gêneros textuais, tais como roteiro, resumo, contos, fábulas, lendas etc., dessa forma os alunos já estarão ambientados. 
e apresentavam seu texto para a turma; escrita - no momento em que tiveram que desenvolver o texto; escuta - no momento em que assistimos aos trailers.

Como professores, devemos sempre pensar em estratégias que alcancem o objetivo de ensinolaprendizagem sem necessariamente estarmos ligados a uma metodologia quadrada e rígida, mas também sem criar métodos mirabolantes que busquem inovar por inovar e não possuam nenhuma base teórica neles. Seria muito mais simples, talvez, levar os alunos ao cinema, assistir a algum filme nacional e depois pedir um resumo do filme, seria uma atividade fora da sala de aula, diferente e aparentemente inovadora, mas o que fundamenta essa prática? Quais propósitos existem por trás dela?

\section{Cultura na língua}

Ao refletir sobre o que propõe Antunes quando afirma que "conhecer uma língua implica conhecer também o conjunto de procedimentos que envolvem seu uso social" (ANTUNES, 2009, p. 37), apresentamos outra atividade que foi realizada com a turma do nível avançado durante os semestres de formação no NUPEL. A aula tinha como tema a interpretação textual e o objetivo era analisar como os alunos estrangeiros interpretavam os textos autênticos que liam. Entre os diferentes textos ${ }^{17}$ selecionados para serem analisados em sala de aula, destacamos um em especial: 'Gatos' fazem Brasil perder energia suficiente para abastecer SC por um ano (LIS, 2018).

A matéria retirada do site do G1 foi publicada em agosto de 2018 e é composta também por gráficos e imagens de 'gatos'. Em posse do texto, os alunos realizaram a leitura junto com o professor. Em seguida, foram levantadas duas questões:

1. O que vocês entendem por 'gatos'?

2. Qual a interpretação que podemos fazer dos gráficos presentes no texto?

Como esperado, nenhum aluno do nível avançado compreendia o significado de 'gato' abordado no texto e, consequentemente, não conseguia interpretar o gráfico que a reportagem trazia. Ao decorrer da atividade notamos a 'cama de gato' em que havíamos nos metido. Conversamos sobre fenômenos linguísticos, fenômenos políticos, aspectos culturais do Brasil e do país de origem dos alunos, consequência dos 'gatos' para o custo

\footnotetext{
17 A atividade não se limitava a analisar textos jornalísticos, mas sim qualquer gênero textual que fornecesse ferramentas de análise linguístico-cultural, tais como canções, poemas etc.
} 
de vida dos brasileiros e também para os estrangeiros etc. Esse exemplo serve para ilustrar a aplicação dos direcionamentos teórico-metodológicos e a importância deles para a prática do professor em formação.

\section{Reflexões finais}

Nas palavras de Clark (2000, p. 76), "a linguagem é fundamentalmente usada com propósitos sociais. As pessoas não simplesmente usam a linguagem. Elas usam a linguagem para fazer as coisas", uma espécie de ação conjunta que se caracteriza pelas atividades sociais nas quais as pessoas estão inseridas. Estabelecer um movimento de práxis no qual você consegue articular a teoria aprendida com a prática exercida é um processo contínuo e circular. Nele, você está inserido como corpo de órbita, sujeito à reflexão e ação constante. No NUPEL esse processo se deu primeiramente com Schön (2000), assim o professor poderia entender suas ações como parte de um processo de aprendizado. Em seguida, relacioná-las e aplicá-las com preceitos teóricos, tais quais Clark (2000) e Antunes (2009), dialogando com a interculturalidade abordada em Mendes (2015).

As atividades apresentadas neste texto não escaparam do processo de análise e reflexão. Para isso, foram elaboradas algumas questões que servem para orientar o professor durante seu processo de autoanálise.

1. Como foi a recepção da atividadeltarefa pelos alunos?

2. A execução da atividade permitiu que os alunos desenvolvessem habilidades previstas no planejamento do curso?

3. A tarefa estava relacionada com os direcionamentos teóricos propostos na formação do professor e na concepção de linguagem escolhida para o ensino dos alunos?

4. Houve efeitos inesperados durante a aplicação da atividade?

5. O que pode ser melhoradolalterado na atividade para uma futura aplicação? Esses questionamentos serviram para guiar o professor durante a autoavaliação das suas propostas pedagógicas e podem ser reformulados sempre que preciso.

As aulas e atividades que foram relatadas aqui não refletem um cenário estanque de formação, mas sim, buscam narrar um período específico em que esse processo ocorreu. Da mesma forma, as atividades desenvolvidas no NUPEL com as turmas de PLE 
não se resumiam a atividades dentro da sala de aula. Entendemos a importância das experiências vividas em sala, afinal, o que seria de nós, professores pesquisadores, sem os nossos laboratórios, entretanto, vale ressaltar que o processo de ensinolaprendizagem aqui relatado também contou com atividades in loco. Os alunos tiveram a oportunidade de visitar a Casa do Rio Vermelho, onde morou o escritor Jorge Amado e sua esposa Zélia Gattai, e se conectarem com a literatura baiana através de uma total imersão daquilo que eles haviam estudado em sala de aula. Também foram brindados com experiências culturais na cidade de Salvador, desde passeios gastronômicos a exposições e concertos, tudo com o objetivo de se aprender a língua pela cultura e entender a cultura pela língua. Ao final do curso, o professor retornava à sala de aula com o mapa que havia sido construído no primeiro dia, e a partir daí, era a vez dos alunos começarem o seu próprio processo reflexivo. A última pergunta do mapa era, como você se imagina no final do curso? Chegado o "momento final" do curso, os alunos podiam refletir se suas expectativas haviam sido atendidas ou não, ou talvez até superadas, movimento esse que faz com que eles percebam seu amadurecimento durante o processo de aprendizagem.

Como afirmou Mendes (2012), ao apontar que não existe uma concepção de língua correta, mas sim a mais adequada ao propósito, o mesmo se dá com os direcionamentos teóricos-metodológicos apresentados. Eles não se configuram como uma fórmula para o ensino de PLE, muito menos como os únicos direcionamentos existentes, mas sim, como aqueles adequados ao espaço tempo relatado. É importante adaptar as práxis pedagógicas aos propósitos da formação educacional, estando atento, principalmente, aos corpos que buscam aprender português.

\section{Referências}

ALMEIDA FILHO, José Carlos Paes de. Fundamentos de abordagem e formação no ensino de PLE e de outras línguas. 2. ed. Campinas: Pontes Editores, 2018.

ANTUNES, Irandé. Língua, texto e ensino: outra escola possível. Série estratégias de ensino 10. São Paulo: Parábola editorial, 2009.

BRASIL. Instituto Nacional de Estudos e Pesquisas Anísio Teixeira. Documento base do exame Celpe-Bras. Brasília: Instituto Nacional de Estudos e Pesquisas Educacionais Anísio Teixeira, 2020. Disponível em: http://portal.inep.gov.br/informacao-dapublicacao/-/asset publisher/6JYIsGMAMkW1/document/id/6939071. Acesso em: 20 jun. 2021. 
BRASIL. Ministério das Relações. Fundação Alexandre de Gusmão. Propostas curriculares para ensino de português no exterior (seis volumes). Brasília: Ministério das Relações, [2021]. Disponível em: https://funag.gov.br/biblioteca-nova/produto/21-1-1. Acesso em: 15 de Agosto de 2021.

BULLA, Gabriela da Silva; KUHN, Tanara Zingano. Português como língua adicional no Brasil: perfis e contextos implicados. Revista Virtual de Estudos da Linguagem - ReVEL. Novo Hamburgo. v. 18, n. 35, p. 1-28, set. 2020. Disponível em: https://lume.ufrgs.br/handle/10183/223991. Acesso em: 01 jul. 2021.

BULEGON, Mariana. Luz, câmera, ação!: prática cinematográfica em aula de português como língua adicional. 2017. Trabalho de Conclusão de Curso (Bacharelado em Letras) - Instituto de Letras, Universidade Federal do Rio Grande do Sul, Porto Alegre, 2017. Disponível em: https://lume.ufrgs.br/handle/10183/178816. Acesso em: 07 jul. 2021.

BULEGON, Mariana; BULLA, Gabriela da Silva; HILGERT, Ananda Vargas. Prática Cinematográfica: o cinema como potencial ético-estético e transdisciplinar na aula de português como língua adicional. Revista Ibero-Americana de Estudos em Educação, Araraquara, v. 13, n. 5, p. 1832-1850, 2018. Disponível em:

https://periodicos.fclar.unesp.br/iberoamericana/article/view/11806. Acesso em: 19 jul. 2021.

CLARK, Herbert. O uso da linguagem. Cadernos de tradução, Porto Alegre, v. 9, p. 4971, 2000.

CARVALHAL, Tatiana Pereira. A Licenciatura em PLE na Universidade Federal da Integração Latino-Americana. In: SCARAMUCCI, Matilde; BIZON, Ana Cecília C. (org.). Formação inicial e continuada de professores de Português Língua Estrangeira / Segunda Língua no Brasil. Araraquara: Letraria, 2020. v. 1, p. 63-77.

CRUZ, Sara Oliveira da. Fiz um blog, e daí? Uma experiência sobre o ensino e a formação inicial de professores de português como língua estrangeira/segunda língua em perspectiva intercultural e crítica. 2019. Dissertação (Mestrado em Língua e Cultura) - Instituto de Letras, Universidade Federal da Bahia, Salvador, 2019. Disponível em: http://www.ppglinc.letras.ufba.br/pt-br/fiz-um-blog-e-dai-uma-experiencia-sobre-oensino-e-formacao-inicial-de-professores-de-portugues-como. Acesso em: 20 jul. 2021.

DINIZ, Leandro Rodrigues Alves. Mercado de linguas: a instrumentalização brasileira do portugues como lingua estrangeira. 2008. Dissertação (Mestrado em Linguística) Instituto de Estudos da Linguagem, Universidade Estadual de Campinas, Campinas, 2008. Disponível em: http://www.repositorio.unicamp.br/handle/REPOSIP/271065. Acesso em: 15 ago. 2021.

LIS, Laís. 'Gatos' fazem Brasil perder energia suficiente para abastecer SC por um ano. G1, Brasília, 25 ago. 2018. Disponível em: https://g1.globo.com/economia/noticia/2018/08/25/gatos-fazem-brasil-perder-energiasuficiente-para-abastecer-sc-por-um-ano.ghtml. Acesso em 20 de Agosto de 2021.

MENDES, Edleise. O conceito de língua em perspectiva histórica: reflexos no ensino e na formação de professores de português. In: LOBO, Tânia et al. Linguística histórica, 
história das línguas e outras histórias. Salvador: EDUFBA, 2012.

MENDES, Edleise. A ideia de cultura e sua atualidade para o ensino-aprendizagem de LE/L2. Revista EntreLínguas, Araraquara, v. 1, n. 2, p. 203-222, jul./dez. 2015.

Disponível em: https://periodicos.fclar.unesp.br/entrelinguas/article/view/8060. Acesso em: 12 jul. 2021.

MENDES, Edleise. A Licenciatura em PLE/PL2 na Universidade Federal da Bahia: formando professores para a diversidade. In: SCARAMUCCI, Matilde; BIZON, Ana Cecília C. (org.). Formação inicial e continuada de professores de Português Língua Estrangeira / Segunda Língua no Brasil. Araraquara: Letraria, 2020. v. 1, p. 41-62.

NIEDERAUER, Marcia et al. A Licenciatura em PBSL e o programa de PLE na Universidade de Brasília: histórico, desafios e perspectivas. In: SCARAMUCCI, Matilde; BIZON, Ana Cecília C. (org.). Formação inicial e continuada de professores de Português Língua Estrangeira / Segunda Língua no Brasil. Araraquara: Letraria, 2020. v. 1, p. 1940.

RODRIGUES, Lucas. Uma experiência de aprendizagem com o português $L E / L 2$ na Bahia - Brasil: percepções dos aprendentes pré-PEC-G (UFBA) sobre a pedagogia de projetos. 2019. Dissertação (Mestrado em Língua e Cultura) - Universidade Federal da Bahia, Salvador, 2019. Disponível em: https://repositorio.ufba.br/ri/handle/ri/31520. Acesso em: 10 jul. 2021.

RODRIGUES, Lucas; OLIVEIRA, Sara Cruz; MENDES, Edleise. O português língua estrangeira (ple)/segunda língua (pl2) na UFBA: institucionalização, desafios e prospecções. Estudos Linguísticos e Literários, Salvador, n. 68, p. 648-669, 2020. Disponível em: https://periodicos.ufba.br/index.php/estudos/article/view/41958. Acesso em: 01 ago. 2021.

SCARAMUCCI, Matilde; BIZON, Ana Cecília C. O PLE na UNICAMP: da implantação da área à formação de professores. In: SCARAMUCCI, Matilde; BIZON, Ana Cecília C. (org.). Formação inicial e continuada de professores de Português Língua Estrangeira / Segunda Língua no Brasil. Araraquara: Letraria, 2020. v. 1, p. 79-112.

SCHOFFEN, Juliana Roquele; MARTINS, Alexandre Ferreira. Políticas linguísticas e definição de parâmetros para o ensino de português como língua adicional: perspectivas portuguesa e brasileira. Revista Virtual de Estudos da Linguagem-ReVEL, Novo Hamburgo, v. 14, n. 26, p. 271-306, mar. 2016. Disponível em: http://www.revel.inf.br/files/c35e818efe36c34dda7b55fdcf72b0fe.pdf. Acesso em: 30 jun. 2021.

SCHÖN, Donald Alan. Educando o profissional reflexivo: um novo design para o ensino e a aprendizagem. Tradução Roberto Cataldo Costa. Porto Alegre: Artes Médicas Sul, 2000.

SILVA, Meire Celedônio da; LEURQUIN, Eulália Vera Lúcia Fraga. Experiência de formação docente e de elaboração de material didático para o ensino de Português como língua estrangeira. In: SIMPÓSIO INTERNACIONAL DE ENSINO DE LÍNGUA 
QUEIROZ, N.; SOUZA, I. L.

PORTUGUESA, 4., 2014, Uberlândia. Anais [...]. Uberlândia: EDUFU, 2014, p. 1-9.

Submetido em: 01 out. 2021. Aceito em: 21 out. 2021. 